Osho PO et al.

\title{
A Case Report
}

\section{Acute Infectious Purpura fulminans in A 2 Year Old Child}

\author{
Osho $\mathrm{PO}^{1}$, Adaja $\mathrm{TM}^{2}$, Odunlade $\mathrm{O}^{3}$, Ige $\mathrm{O}^{4}$, Ojo MAO${ }^{1}$, Modupe $\mathrm{BO}^{3}$, \\ Joseph $\mathbf{A A}^{5}$, Adeyemi $\mathbf{M E}^{1}$ \\ ${ }^{\prime}$ Departments of Haematology Blood transfusion, ${ }^{2}$ Chemical \\ Pathology, ${ }^{3}$ Paediatrics, ${ }^{4}$ Surgery and ${ }^{5}$ Microbial Pathology, \\ Faculty of Basic Clinical Sciences, University of Medical \\ Sciences, Ondo-City, Nigeria.
}

\author{
Correspondence \\ Dr Patrick O. Osho \\ Email:droshopo@gmail.com
}

\begin{tabular}{ll}
\hline Article Metrics & \\
Date submitted: & $11 / 05 / 2020$ \\
Date Accepted: & $04 / 06 / 2020$ \\
Date Published: & June, 2020
\end{tabular}

\section{ABSTRACT}

Purpura fulminans (PF) is a rapidly progressing clinical syndrome of haematologic and cutaneous manifestations accompanied by an underlying dysfunction of coagulation resulting in disseminated intravascular coagulation (DIC). It is a life threatening haematologic emergency characterized by extensive skin necrosis with haemorrhagic infarction, hypotension and gangrene which may arise from severe sepsis, mostly gram negative organisms. Some gram positive organisms and viral infections have been implicated in the aetiology of PF. We reported a case of purpura fulminans in a 2 year old boy with severe sepsis and peripheral gangrene from gram positive coccus (Staphylococcus aureus). Even though we were faced with limitations in terms of laboratory support and parental financial constraints in the management of the patient; he survived mainly on supportive care and antibiotics.

Keywords: Sepsis, Purpura fulminans, disseminated intravascular coagulation (DIC), .

\section{INTRODUCTION}

$P$ urpura fulminans (PF) was first described by Guelliot in 1884, ever since; several cases have been reported. The French researcher noticed gangrenous-like cutaneous manifestations that rapidly developed among a population of his patients who contracted certain infections. ${ }^{2}$ It is a medical emergency requiring prompt diagnosis and management, ${ }^{3} \mathrm{PF}$ is characterized by an acute purpuric rash characterized by coagulation of microvasculature leading to cutaneous necrosis. ${ }^{4}$ There are three forms of purpura fulminans viz; neonatal-, idiopathic- and acute infectious purpura fulminans. Neonatal purpural fulminans is characterized by hereditary deficiency of anticoagulants protein $\mathrm{C}, \mathrm{S}$ and antithrombin III. ${ }^{5}$ Idiopathic purpura fulminans is a post-infectious autoimmune disorder following an initial febrile illness which later progressed to purpura. Acute infectious purpura fulminans (AIPF) is the commonest form of PF found in severe septic patients with predilection to certain infectious agents such as in meningococcal, streptococcal, staphylococcal, gram negative sepsis and falciparum malaria. ${ }^{6,7}$ AIPF is also seen in physically or functionally asplenic patients. Purpura fulminans is common in infants and younger children, often associated with multiple organ failure and death. ${ }^{1}$ Studies have shown that Klebsiella species are found to be associated with PF in children in Nigeria. ${ }^{2,8}$

The acute inflammatory response found in sepsis activates coagulation and complement cascades leading to endothelial injury, usually triggers disseminated 
Osho PO et al.,

intravascular coagulopathy (DIC). ${ }^{9}$ The consumption of clotting factors and platelets leads to bleeding, while loss of key anticoagulants, protein $\mathrm{C}$ and co-factor protein $\mathrm{S}$, promotes thrombosis, inhibits fibrinolysis and further activate inflammation. ${ }^{10}$

PF may lead to auto-or surgical amputation in up to $50 \%$ of survivors and a mortality of up $52 \%$ has been documented. ${ }^{10,11}$ Although the pathology once triggered is irreversible, prompt identification of potential risk factors with early haematologic evaluation and intervention provides timely appropriate management to reduce mortality and prevent debilitating tissue damage. The case reported here highlights the need for high index of suspicion in a child presenting with sepsis along with other risk factors for PF.

\section{CASE REPORT}

A 2year old boy presented with fever, yellowness of the eyes and diarrhea for 5 days. No history of reduced urinary output. However, he was extremely weak and without improvement despite the over-the-counter drugs. He was conscious, and in obvious respiratory distress.

Examination reveals a critically ill child, febrile (temperature of 39.9 C), pale, deeply icteric, dehydrated with cold clammy extremities. Respiratory system examination revealed a dyspneic child as evidenced by grunting respiration, flaring nares and subcostal as well as intercostal recessions, and crackles sound heard globally on auscultation. The heart rate was 184 beats per minute with haemic murmur. Oxygen saturation in room air (SP02) was 55\%. An assessment of Anaemic heart failure secondary to severe malaria/sepsis was made.

He was resuscitated with IV fluids and intranasal oxygen was commenced. An urgent packed cell volume (PCV) done was $7 \%$ and he had blood transfusion twice. He was also commenced on parenteral ceftriaxone and gentamicin, as well as parenteral anti-malaria. $\mathrm{His}_{\mathrm{SPO}}$ improved to $78 \%$ following the initial blood transfusion.

Five days after admission, his condition gradually improved, the diarrhoea has stopped, vital sign has

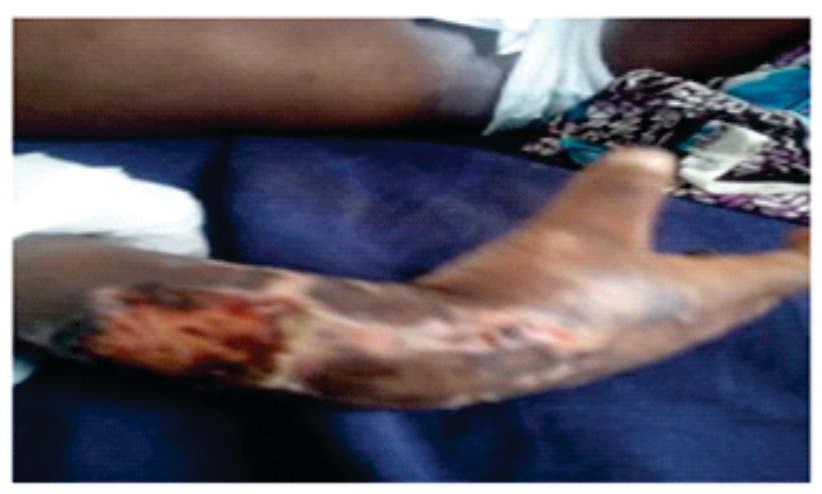

A

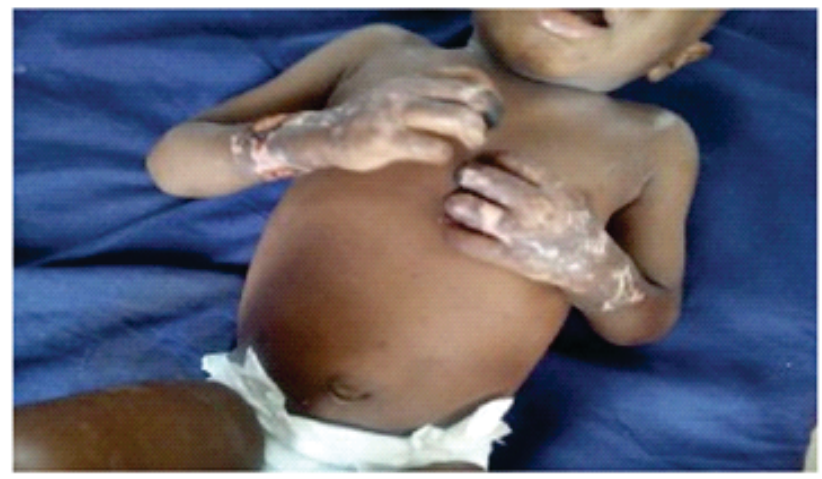

B

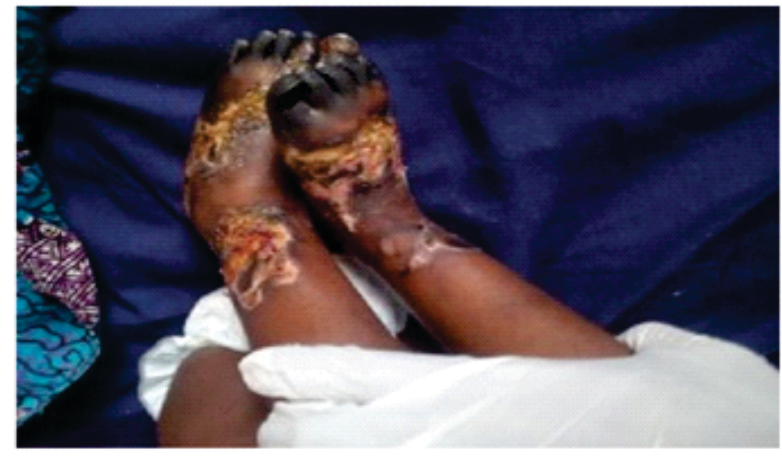

C

Figure 1: A-C; Diffuse purpuric rashes of the upper and lower limbs with gangrene of the digits 
Table 3: Microbiological evaluation findings in the patient

\begin{tabular}{lll}
\hline Test category & Components & $\begin{array}{l}\text { Results at presentation } \\
\text { Blood culture }\end{array}$ \\
& $\begin{array}{l}\text { Culture } \\
\text { Sensitivity }\end{array}$ & $\begin{array}{l}\text { Growth of gram positive coccus ( Staphylococcus aureus } \\
\text { Sensitive to: ceftriazone, gentamicin, and azithromycin } \\
\text { Resistant to: Augumentin. }\end{array}$ \\
Viral studies & HBsAg & Negative \\
& HCV & Negative \\
& HIV-1\&2 & Negative \\
Malarial test & Thick film & Negative \\
\hline HBsAg:Hepatitis & B surface antigen, HIV:Human immunodeficiency virus. HCV:Hepatitis C virus
\end{tabular}

improved with $\mathrm{SPO}_{2}-92 \%$ at room air; respiratory rate was 30 cycles $/ \mathrm{min}$, heart rate was at 96 beat $/ \mathrm{min}$, but still febrile. There was poor compliance with medications as outlined due to financial constraint. Ecchymotic patches began to appear on the lower extremities and ischemic patches on the toe nails and upper extremities symmetrically, with associated tenderness and non-pitting edema up to the ankle. The ecchymotic and purpura lesions were progressing from the toes and fingers to the distal 3rd of the legs and fore arm respectively. Proximal part of the lesion was demarcated by blisters. The radial and popliteal pulses were palpable on both sides. The posterior tibial and dorsalis pedis pulses were not palpable on either side.

Investigation done revealed abnormalities suggestive of severe sepsis (peripheral blood film showed markedly increase granulocytes and left shift with toxic granulation) features of evolving DIC, (polychromatic cells, numerous target cells, thrombocytopenia and fragmented cell), deranged clotting profile and liver function test parameters. Malaria parasite test was positive. Further evidence for DIC (plasma D-dimer, fibrinogen level and urinary fibrinogen degradation product (FDP) and doppler ultrasound were unavailable due to financial constraints. Blood culture yielded gram positive coccus organism sensitive to ceftriazone, gentamicin, and azithromycin. We commenced intravenous metronidazole and hydrocortisone upon the appearance of the ecchymotic lesions.

Exchange blood transfusion was not done as the parents refused the procedure despite thorough counselling. The overlying skin became darker while the limbs were immobile with loss of touch sensation at the extremities. Fresh frozen plasma and heparin were considered for use but was not readily available due to financial constraints. Orthopaedic and plastic surgical teams were invited for possible amputation of the gangrenous toes which was rejected by the parents even after counseling. Intravenous antibiotics were continued and he was subsequently discharged after a month for follow up. At discharge patient had improved significantly. There was improvement in the ecchymotic lesion and fever has subsided. The boy was discharged in a good clinical status and is being followed up in the clinic. 
Table 1: Haemotologic parameters of the patient

\begin{tabular}{llll}
\hline Test category & Components & $\begin{array}{l}\text { Results at } \\
\text { presentation }\end{array}$ & $\begin{array}{l}\text { Results at the time of } \\
\text { discharge }\end{array}$ \\
\hline Full blood count & White blood cell & $12.4 \times 10^{9} / \mathrm{L}$ & $10.2 \times 10^{9} / \mathrm{L}$ \\
& Red blood cell* & $0.8 \times 10^{9} / \mathrm{L}$ & $3.2 \times 10^{9} / \mathrm{L}$ \\
& Neutrophil & $80 \%$ & $70 \%$ \\
& Lymphocytes & $22 \%$ & $26 \%$ \\
& Platelets* & $74,000 / \mathrm{L}$ & $80,000 / \mathrm{L}$ \\
& Haematocrit* & $7 \%$ & $24 \%$ \\
& Haemoglobin concentration* & $2 \mathrm{~g} / \mathrm{dL}$ & $8 \mathrm{~g} / \mathrm{dL}$ \\
& Mean corpuscular volume & $86 \mathrm{fL}$ & $88 \mathrm{fL}$ \\
& MCHC & $30 \mathrm{~g} / \mathrm{dL}$ & $32 \mathrm{~g} / \mathrm{dL}$ \\
& Red blood cell: & & Anisopoikilocytosis \\
& & & Polychromatic cells \\
& & & Numerous target cells \\
& & & Fragmented cells \\
& & & Leucocytosis \\
& & & Left shift \\
& White blood cells & & Hypersegmented neutrophils \\
& & & Atypical lymphoid cells \\
& & & Thrombocytopaenia \\
& & 47 seconds & 43seconds \\
& & 88 seconds & 71 seconds \\
& Platelets: &
\end{tabular}

Table 2: Biochemical profile of the patient

\begin{tabular}{lllll}
\hline $\begin{array}{l}\text { Test } \\
\text { category }\end{array}$ & Analytes & $\begin{array}{l}\text { Lab values at } \\
\text { presentation }\end{array}$ & $\begin{array}{l}\text { Lab values at the point of } \\
\text { discharge }\end{array}$ & $\begin{array}{l}\text { Reference } \\
\text { intervals }\end{array}$ \\
\hline Kidney & Sodium ion & $140 \mathrm{mmol} / \mathrm{L}$ & $135 \mathrm{mmol} / \mathrm{L}$ & $135-145$ \\
& Potassium ion & $4.0 \mathrm{mmol} / \mathrm{L}$ & $4.6 \mathrm{mmol} / \mathrm{L}$ & $3.5-5.0$ \\
& Chloride ion & $94 \mathrm{mmol} / \mathrm{L}$ & $98 \mathrm{mmol} / \mathrm{L}$ & $95-105$ \\
& Bicarbonate ion & $22 \mathrm{mmol} / \mathrm{L}$ & $21 \mathrm{mmol} / \mathrm{L}$ & $20-30$ \\
& Urea & $4.0 \mathrm{mmol} / \mathrm{L}$ & $4.1 \mathrm{mmol} / \mathrm{L}$ & $2.5-6.0$ \\
Liver & Creatinine & $83 \mu \mathrm{mol} / \mathrm{L}$ & $93 \mu \mathrm{mol} / \mathrm{L}$ & $55-100$ \\
& Total protein & $7.2 \mathrm{~g} / \mathrm{dL}$ & $6.7 \mathrm{~g} / \mathrm{dL}$ & $6.4-8.4$ \\
& Albumin & $4.1 \mathrm{~g} / \mathrm{dL}$ & $3.6 \mathrm{~g} / \mathrm{dL}$ & $3.0-5.5$ \\
& ALT* & $20 \mathrm{IU} / \mathrm{L}$ & $35 \mathrm{IU} / \mathrm{L}$ & $<12$ \\
& AST* & $16 \mathrm{IU} / \mathrm{L}$ & $26 \mathrm{IU} / \mathrm{L}$ & $<12$ \\
& ALP & $302 \mathrm{IU} / \mathrm{L}$ & $289 \mathrm{IU} / \mathrm{L}$ & $90-360$ \\
& GGT & $23 \mathrm{IU} / \mathrm{L}$ & $33 \mathrm{IU} / \mathrm{L}$ & $30-78$ \\
Tlucose & Total bilirubin* & $2.8 \mathrm{mg} / \mathrm{dl}$ & $1.4 \mathrm{mg} / \mathrm{dl}$ & $<1.0$ \\
\hline ALT: Alanine aminotransferase, AST:Aspartate aminotransferase, ALP:Alkaline phosphatase, GGT: Gammaglutamyl transferase, \\
RPG:Random plasma glucose & & $0.3 \mathrm{mg} / \mathrm{dl}$ & $<0.4$ \\
\end{tabular}




\section{DISCUSSION}

Purpura fulminans is a rare but rapidly progressing thrombotic disorder manifesting with widespread purpura. ${ }^{12}$ This condition has been associated with a high mortality rate of $35 \%$ or more, although recent advances in diagnosis and treatment strategies have reduced mortality. ${ }^{3}$ Skin findings of PF have a characteristic nonblanching dark red-to-purple appearance, which distinguish them from other purpuric lesions. ${ }^{13}$ Erythema is rapidly followed by irregular central area of blue-black hemorrhagic necrosis with a surrounding erythematous border ${ }^{14} \mathrm{PF}$ usually presents with cutaneous vesicles and bullae. The lesions are tender, raised, angulated. The necroses can be widespread and involve the deep muscle and sometimes the bone. Healing leads to scaring and auto-amputation of digits and extremities can occur. ${ }^{15}$

Purpura fulminans lesions have characteristic erythema with central areas of blue-black haemorrhagic gangrenous necrosis with a surrounding erythematous border. ${ }^{16}$ In this case; we isolated Staphylococcus aureus as the culprit for acute infectious purpura fulminans (AIPF). Staphylococcal AIPF, initially reported as rare, becoming a common occurrence among diverse group of patients. ${ }^{17}$ Toxin shock syndrome toxin-1 producing Staphylococcus aureus has been found to be an under recognized aetiologic agent in purpura fulminans. ${ }^{18}$ Even though we isolated S. aureus in the blood of the patient but we were unable to demonstrate if it was TSST-1 producing- or methicillin resistant Staphylococcus aureus (MRSA) as both strains have been widely documented as common cause of $\mathrm{PF} .{ }^{19}$

The clinical improvement of this patient can be adduced to prompt commencement of broad spectrum antibiotic (intravenous ceftiazone) after specimen collection, haemodynamic stability following blood transfusion, as well as normal organ function. There was biochemical derangements seen in liver function test and the Full blood count and peripheral blood film done also showed features of sepsis.
PF occurs predominantly in three clinical setting. Firstly is the most common inherited or acquired defect in protein $\mathrm{C}$ or S. The hematologic derangement usually leads to a more benign presentation that does not usually lead to sepsis. The purpuric lesions usually start in the distal limbs and progress proximally ${ }^{6}$. It has been documented more in neonate but can also be seen in adults. The idiopathic PF occurs 7-10days after a relatively benign antecedent infection usually of the skin, such as varicella, scarlet fever rubella, measles, streptococcal tonsillopharyngitis etc. ${ }^{7}$ Acute infectious purpura fulminans which occurs in the case discussed earlier in conjunction with acute infectious illness particularly sepsis with endotoxins (lipopolysaccharide) producing gramnegative and positive bacteria. ${ }^{20}$ However most cases of acute infectious $\mathrm{PF}$ associated with meningococcal sepsis but can also occur with other organisms in the setting of septicaemia with DIC. Other organisms which have been reported to cause acute infectious PF are Streptococcus pnemoniae, Streptococcus pyogenes, Staphylococous aureus, Klebsellapnemoniae, E. coli, Proteus mirabilis, Neiseria catarrhalis, Capnocytophagasppetc. ${ }^{20}$ Approximately 60 to $70 \%$ cases of acute PF have been reported among children of 2 years of age and above. ${ }^{20}$

The occurrence of sepsis, dehydration and shock in this child were potent predisposing factor for purpura fulminans and DIC, thus contributing to the development of gangrene. ${ }^{1}$

Two cases of severe malaria patients presenting with $\mathrm{PF}$ has been reported in literature, ${ }^{7}$ malaria wasalso documented in this child. The haematologic and coagulation derangements along with thrombocytopenia observed suggested the evolving DIC. However lack of protein $\mathrm{C}$, protein S, Antithrombin III and plasma/ urinary FDPs assay constituted major limitations to completeness of laboratory evaluation in this child, especially as these parameters are useful for confirmation and staging of DIC. ${ }^{1,11,20}$

The empirical choice of intravenous ceftriaxone /gentamicin for the isolated organism gave a good clinical 
response. Lack of platelet concentrate, coagulation factor, protein $\mathrm{C}$ and $\mathrm{S}$, antithrombin III concentrates and non availability of fresh frozen plasma due to financial constraints, which are known to be beneficial in patients with PF and DIC constituted some of the limitations encountered in this patient.

\section{CONCLUSION}

Purpura fulminans is a rare clinical condition that should be promptly recognized and empirically treated. Emperical use of antibiotics is advocated especially if the patient has features suggestive of sepsis and disseminated intravascular coagulopathy. Early recognition and prompt management are crucial in reducing morbidity and mortality in patients with purpura fulminans. Despite limitations posed by laboratory support and financial constraints, the outcome in this patient was good due to prompt use of intravenous broad spectrum antibiotics and other supportive therapies.

\section{Recommendation}

We recommend early recognition and prompt management of purpura fulminans in order to reduce morbidity and mortality.

\section{Competing Interest}

We hereby state that there is no competing interest in this report.

\section{REFERENCES}

1. Umar LW, 'Yauba MS, Olorukooba AA, Abubakar Y, Mohammed AJ, Chom ND. Purpura Fulminans with Disseminated Intravascular Coagulopathy. Annals of Medical and Health Sci Research. 2017;7 (2):69-72.

2. Rahul S, Sowmya N, John NG. Purpura Fulminans: A Case Report and Review of All Causes Infectious Diseases in Clinical Practice 2017;25:29.

3. Kumar A, Shah NP, Menon V, Nissen SE. Purpura fulminans manifesting with Staphylococcus aureus endocarditis. Europ Heart Journal- Case reports 2019;3(2):ytz077.

4. Findley T, Patel M, Chapman J, Brown D, Duncan AF.
Acquired Versus Congenital Neonatal Purpura Fulminans: A Case Report and Literature Review. J. Pediatr. Hematol. Oncol. 2018 Nov;40(8):625-627.

5. Kizilocak H, Ozdemir N, Dikme G, Koc B, Celkan T. Homozygous protein $\mathrm{C}$ deficiency presenting as neonatal purpura fulminans: management with fresh frozen plasma, low molecular weight heparin and protein $C$ concentrate. J. Thromb. Thrombolysis. 2018 Feb;45(2):315-318.

6. Honarpisheh H, Camp R, Lozova R. Staphylococcal purpura fulminans: Report of a case. Am. J. Dermatopathol 2015; 37(8):643-6

7. Fowotade A, Oladokun RE et al. Purpura fulminans with peripheral gangrene in severe Falciparum malaria. Journal of Case Report. 2018; 8(1) 27-32

8. Levi M, van der Poll T. Inflammation and coagulation. Crit Care Med. 2010;38:S26-34.

9. GhosK SK, Bandly Opadhyay D. Symmentrical peripheral gangrene. IncliJ Dermatol Venero Leprol. 2011; 77; 244248.

10. Kaira OP Agarwal S, Khaira A. Acute infections Purpura fulminians due to klebsiella pneumonia: a case report. JIACM. 2003; 4(2): 156-58

11. Lamadrid-Zertuche AC, Garza-Rodríguez V, OcampoCandiani JJ. Pigmented purpura and cutaneous vascular occlusion syndromes. An Bras Dermatol. 2018 Jun;93(3):397-404.

12. Colling ME, Bendapudi PK. Purpura Fulminans: Mechanism and Management of Dysregulated Hemostasis. Transfus Med Rev. 2018 Apr;32(2):69-76.

13. Jaconelli T, PsiridisA. A fulminant rash. New Z. Med J.2009; 122:73-74

14. Chalmers E, Cooper P, Forman K, et al. Purpura fulminans: recognition, diagnosis and management. Arch Dis Child 2011;96:1066-71.

15. Kizilocak H, Ozdemir N, Dikme G, Koc B, Celkan T. Homozygous protein $\mathrm{C}$ deficiency presenting as neonatal purpura fulminans: management with fresh frozen plasma, low molecular weight heparin and protein $\mathrm{C}$ concentrate. J. Thromb. Thrombolysis. 2018 Feb;45(2):315-318.

16. Kravitz GR, Dries DJ, Peterson ML, Schlievert P. Purpura fulminans due to S. aureus. Clin Infectious Disease 2005;40(7):941-7.

17. Honarpisheh H, Camp R, Lozova R. Staphylococcal purpura fulminans: Report of a case. Am. J. Dermatopathol 2015; 37(8):643-6.

18. Fitzgerald CJ, Pranikoff TV, Ross GA, Mou S, Givner LB. Purpura fulminans caused by community associated MRSA. Case Report 2012;30(6):1013.E1-1013.E4.

19. Kaira OP Agarwal S, Khaira A. Acute infections Purpura fulminians due to Klebsiella pneumoniae: a case report. JIACM. 2003; 4(2): 156-58

20. Olowu WA. Klebsiella induced Purpura fulminans in Nigerian child: case report and a review of Literature. WAJM. 2002; 21:253-256. 